\title{
Behavior of Boron in Molten Aluminum and its Grain Refinement Mechanism
}

\begin{abstract}
HOUSHANG D. ALAMDARI, DOMINIQUE DUBÉ, and PASCAL TESSIER
The mechanism of heterogeneous grain refining of aluminum by ultrafine elemental boron particles was investigated. In order to facilitate the observation of the boron-aluminum interface, a boron filament was introduced in a melt at $1013 \mathrm{~K}\left(740{ }^{\circ} \mathrm{C}\right)$ containing different levels of $\mathrm{Ti}$. The Al/B interface was studied using transmission electron microscopy and different phases were identified using the electron diffraction method. The experimental results showed that boron is dissolved in pure aluminum while its dissolution is inhibited in presence of titanium solute. A thin layer of $\mathrm{TiB}_{2}$ formed at the surface of boron thickens with residence time in the melt. The mechanisms by which aluminum is crystallized on boron are discussed.
\end{abstract}

DOI: $10.1007 / \mathrm{s} 11661-012-1388-\mathrm{x}$

(C) The Minerals, Metals \& Materials Society and ASM International 2012

\section{INTRODUCTION}

THE addition of grain refiners into molten aluminum alloys is a common industrial practice to suppress the growth of columnar grains, to promote the formation of fine grains, and to improve castability and product quality. Grain refiners are usually added as Al-based master alloys that are rich in at least one of the following elements: titanium, boron and carbon. There are several types of grain refiners. Those produced by reaction of molten aluminum with halide salts $\left(\mathrm{K}_{2} \mathrm{TiF}_{6}\right.$ and $\left.\mathrm{KBF}_{4}\right)$ and containing 5 pct Ti and 1 pct $\mathrm{B}$, are the most widely used by industry. Their typical microstructure consists of $\mathrm{TiB}_{2}$ particles, $\mathrm{TiAl}_{3}$ needles and $\mathrm{Ti}$ solute in an aluminum matrix. Small additions of such master alloys in aluminum alloys (usually at $0.01 \mathrm{pct} \mathrm{Ti}$ and $0.002 \mathrm{pct}$ $B$ levels) result in a fine and equiaxed solidification microstructure. An appropriate temperature of addition practically lies between the liquids and $1073 \mathrm{~K}\left(800^{\circ} \mathrm{C}\right)$.

A great deal of fundamental research has been done over the past 50 years in order to understand the possible mechanisms by which grain refiners yield a fine microstructure. The majority of fundamental research works have focused on the refining mechanisms of Al-Ti-B master alloys and several theories have been postulated in this matter which were summarized in very useful comprehensive reviews. ${ }^{[1-4]}$ According to these theories, the refinement effect could be ascribed to two phenomena: (i) the growth restriction factor and (ii) the inoculation and heterogeneous nucleation. The growth restriction is explained by the diffusion of solute atoms at the liquid/solid interface. In the inoculation theory,

HOUSHANG D. ALAMDARI and DOMINIQUE DUBÉ, Professors, are with the Department of Mining, Metallurgical and Materials Engineering, Laval University, Quebec, QC, G1K 7P4, Canada. Contact e-mail: Houshang.alamdari@gmn.ulaval.ca PASCAL TESSIER, Senior Research Scientist, is with Air Liquide Research and Development, Delaware Research and Technology Center, 200 GBC Drive, Newark, DE, 19702.

Manuscript submitted February 7, 2012.

Article published online September 13, 2012 however, $\alpha$-Al grains grow on the nucleation sites that are introduced in the liquid metal by the master alloy. Small particles of $\mathrm{TiAl}_{3}$, (Ti-Al) $\mathrm{B}_{2}$, and $\mathrm{TiB}_{2}{ }^{[5-9]}$ have been proposed as potential nuclei contributing to the formation of $\alpha-\mathrm{Al}$ and the efficiency and stability of these particles have been extensively studied. According to a general consensus, the heterogeneous nucleation of aluminum is attributed to the presence of $\mathrm{TiB}_{2}$ particles when an Al-Ti-B refiner is used. Some experimental evidence confirmed the nucleation potential of $\mathrm{TiB}_{2}$ particles, while it was also shown that $\mathrm{TiB}_{2}$ could be surrounded by a thin layer of $\mathrm{TiAl}_{3}$ phase which acts as the nucleation site. ${ }^{[10-15]}$

Although the efficiency of grain refiners has been improved considerably over the past decades, there are still several issues which need to be addressed. One of these issues is the difficulty of controlling the size, morphology and agglomeration of $\mathrm{TiB}_{2}$ particles in $\mathrm{Al}$-Ti-B master alloy. Individual particles of $\mathrm{TiB}_{2}$ have typically a size between 0.5 and $2 \mu \mathrm{m}$ but some reach $10 \mu \mathrm{m}$. Agglomeration of particles increases with increasing residence time in the melt and worsens in the presence of halide salt traces ${ }^{[16,17]}$ although recent studies have shown that $\mathrm{Mg}$ additions reduce the agglomeration and increase nucleation efficiency in Al-Si alloys. ${ }^{[18]}$ The coarse $\mathrm{TiB}_{2}$ particles and agglomerates are a serious concern and can cause surface defects, especially if the aluminum is to be rolled in thin foils. Settling of $\mathrm{TiB}_{2}$ particles is another issue. These particles tend to settle at the bottom of crucibles resulting in the formation of sludge and reducing the overall efficiency of the refiner. Grain refining of recycled aluminum is also a growing concern in cast houses. The level of Ti must be kept under the peritectic concentration in order to prevent the formation of brittle $\mathrm{TiAl}_{3}$ needles during solidification. Recycled metals contain a considerable amount of titanium. Addition of Ti-containing refiners in a recycled metal causes an increase of $\mathrm{Ti}$ level and limits the use of recycled metals in melt charge. Foundries keep this level typically under $1000 \mathrm{ppm}$. Titanium level is controlled 
by mixing recycled and pure aluminum in the melt charge.

In an attempt to overcome some of the abovementioned issues, Alamdari et al. ${ }^{[19]}$ have proposed a novel process for grain refinement of aluminum alloys by using fine elemental boron particles. These grain refiners are in the form of Al-matrix composites in which elemental boron particles are finely dispersed using high energy ball milling. The grain refining tests revealed that the addition of boron alone at the level of 0.002 pct does not provide any grain refining effect in pure aluminum. However they showed that when titanium is introduced prior to or along with boron this refiner is more efficient than the conventional Al-5Ti-1B refiners for commercially pure aluminum and some Al-Si based alloys such as A356 and A357. These observations confirm the fact that boron particles do not survive in pure aluminum above $1013 \mathrm{~K}\left(740{ }^{\circ} \mathrm{C}\right)$. However, in the presence of $\mathrm{Ti}$, boron particles are not only protected in the melt but also contribute efficiently to heterogeneous nucleation of aluminum. Beside its great efficiency and good control of particle size refining, this grain refiner may also offer the possibility of treating recycled aluminum without any titanium addition. The mechanism by which elemental boron particles act as potential nuclei is however still unknown.

The purpose of this paper is to study the behavior of elemental boron in liquid aluminum in order to elucidate its influence on the grain refining mechanism of boron particles. The boron filament was introduced into liquid aluminum containing different concentrations of dissolved titanium and the microstructure and composition at the boron/aluminum interface were studied. The boron fiber facilitates the study of the boronaluminum interface after immersion in liquid aluminum.

\section{EXPERIMENTAL DETAILS}

A series of aluminum melts with titanium levels varying between 20 and $500 \mathrm{ppm}$ were prepared in an alumina crucible using an electric furnace heated at $1013 \mathrm{~K}$ $\left(740{ }^{\circ} \mathrm{C}\right)$. The chemical composition of the pure aluminum used to prepare the melts is given in Table I. For each sample, approximately $200 \mathrm{~g}$ of alloy was melted.

The titanium level in the melt was adjusted by adding a master alloy containing $6 \mathrm{wt}$ pct Ti. The master alloy had been previously prepared in the laboratory by dissolving $6 \mathrm{wt}$ pet pure titanium powder in pure molten aluminum. The required mass of master alloy was added to molten aluminum at $1053 \mathrm{~K}\left(780^{\circ} \mathrm{C}\right)$ prior to stirring and reducing the temperature to $1013 \mathrm{~K}\left(740{ }^{\circ} \mathrm{C}\right)$.

A boron filament (supplied by Specialty Materials Inc., USA) was then introduced into both pure aluminum and Al-Ti melts. Figure 1 shows the surface aspect of the boron filament and reveals its polycrystalline structure. The filament is composed of a tungsten wire of $10 \mu \mathrm{m}$ diameter coated with $70 \mu \mathrm{m}$ thick high purity boron.

In a first series of experiments, boron filaments were immersed into pure aluminum and Al-Ti melts for different periods of time varying between 5 and 15 minutes. In order to provide Al-Ti melts, titanium was added to the melt 30 minutes before introducing the boron filament. The crucible was then taken out of the furnace and allowed to cool rapidly. Duration of solidification was about one minute. The solidified samples were then cut and polished and the cross section of the filament was characterized using optical and scanning electron microscopy in order to reveal the boron-aluminum interface.

In a second series of experiments, two specimens were immersed into the melt for 30 minutes and 6 hours respectively and then rapidly pulled out of the melt in order to allow rapid quenching directly from the melt temperature. This second series of test was performed to eliminate any cooling artifact at the interface and to reveal the interface state as it was in the melt. The specimens were thinned using focused ion beam (FIB) and their interface was examined using a transmission electron microscope (TEM).

\section{RESULTS AND DISCUSSION}

\section{A. Stability of Elemental Boron in Pure Al and Al-Ti Melts}

Figure 2 shows the polished cross-section of a boron fiber after immersion in pure aluminum melt for 5 minutes and solidification. The fiber remained in crucible during solidification (solidification time was about 1 minutes). Figure 3 shows the cross section of a second filament immersed 12 minutes and solidified in identical conditions. As seen, the boron filament dissolves rapidly in pure aluminum melt so that after 12 minutes its diameter was reduced from 150 to $50 \mu \mathrm{m}$. After 15 minutes, the boron filament was completely dissolved in aluminum. These observations confirms that fine boron particles would dissolve very rapidly in pure aluminum at $1013 \mathrm{~K}\left(740{ }^{\circ} \mathrm{C}\right)$ and consequently they do not contribute to the heterogeneous nucleation of aluminum.

Since the grain refining effect of boron particles had been reported in a melt containing at least $100 \mathrm{ppm}$ $\mathrm{Ti},{ }^{[19]}$ the stability of a boron filament in melts having different concentrations of titanium was also investigated in order to reveal the effect of $\mathrm{Ti}$ on boron dissolution rate. Titanium was added to the melt 30 minutes before introducing the boron filament, providing melts containing between 50 and $500 \mathrm{ppm}$ Ti. Figure 4 shows the polished cross section of the

Table I. Chemical Composition of the Liquid Aluminum Bath

\begin{tabular}{lcccccccc}
\hline Element & $\mathrm{Al}$ & $\mathrm{Si}$ & $\mathrm{Fe}$ & $\mathrm{Cu}$ & $\mathrm{Zn}$ & $\mathrm{V}$ & $\mathrm{Pb}$ & $\mathrm{Ti}$ \\
\hline Wt pct & 99.995 & 0.001 & 0.0009 & 0.0009 & $<0.0001$ & $<0.0001$ & $<0.0001$ & $<0.0020$ \\
\hline
\end{tabular}




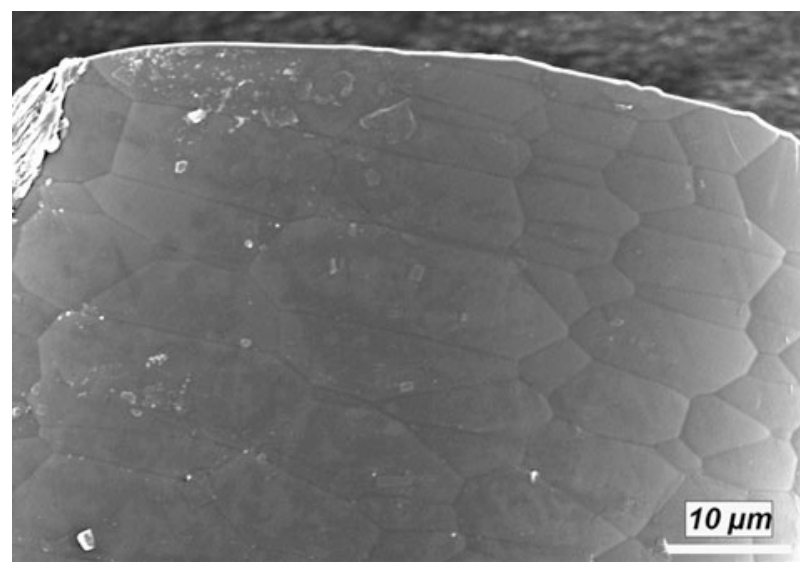

Fig. 1-SEM image of the boron filament surface.

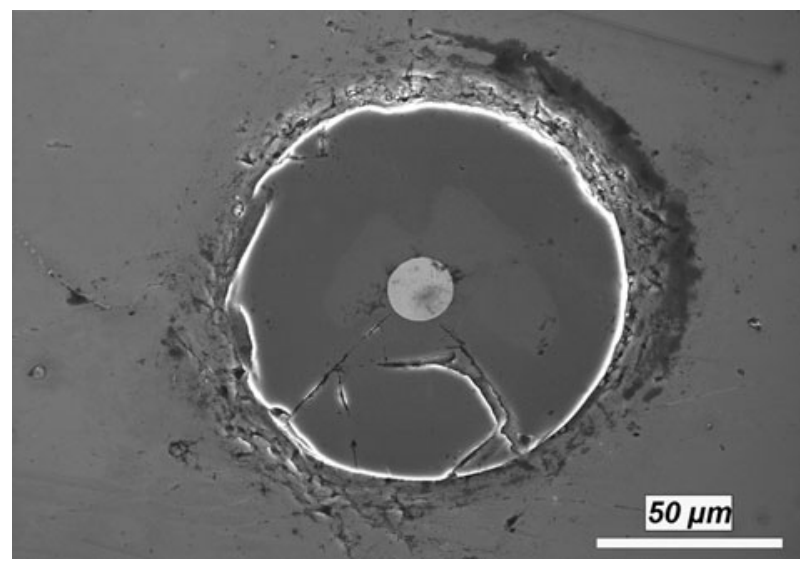

Fig. 2 - Cross-section of a boron fiber that was immersed for $5 \mathrm{~min}$ in pure molten aluminum at $1013 \mathrm{~K}\left(740{ }^{\circ} \mathrm{C}\right)$. The fiber remained in the melt during solidification. The tungsten wire is visible at the center.

boron filament after being kept for 10 minutes in an aluminum melt containing $500 \mathrm{ppm}$ Ti. The fiber remained in the melt during solidification. A similar behavior was observed in melts containing 100, 200 and $500 \mathrm{ppm} \mathrm{Ti}$. This concentration of titanium is typically found in cast industrial alloys. The diameter of the boron filament remains unchanged indicating that this concentration of titanium solute prevents the dissolution of boron in the melt. Even after 6 hours in the melt, the filament kept its initial diameter. The same experiments conducted with lower Ti levels revealed that the amount of $\mathrm{Ti}$ required for protection of boron wire is as low as $150 \mathrm{ppm}$. These observations confirm that the dissolved titanium efficiently stabilizes boron particles in an aluminum melt where they could eventually contribute to heterogeneous nucleation.

\section{B. Boron/Aluminum Interface}

The interface of the boron filament and aluminum matrix was examined after different immersion times in order to understand the mechanisms by which boron is protected in the presence of titanium. First, a boron

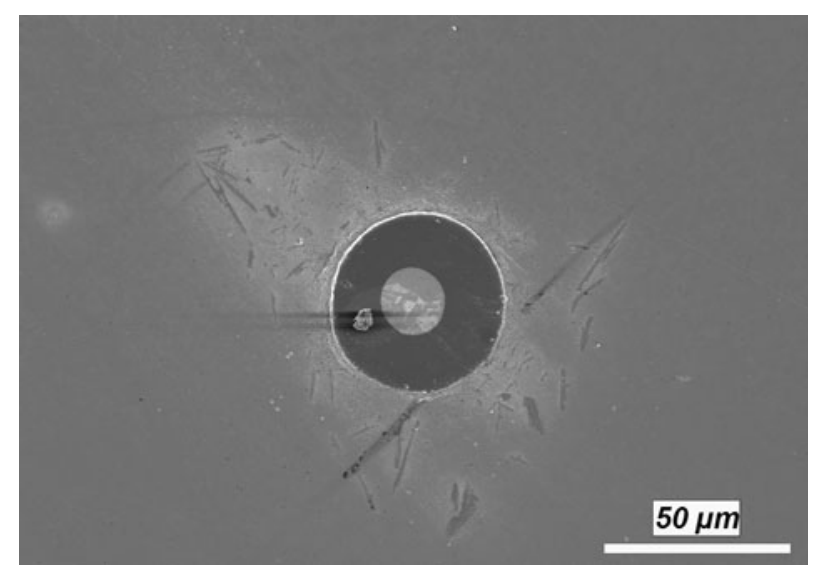

Fig. 3-Cross-section of a boron fiber that was immersed for $12 \mathrm{~min}$ in pure molten aluminum at $1013 \mathrm{~K}\left(740{ }^{\circ} \mathrm{C}\right)$. The fiber remained in the melt during solidification.

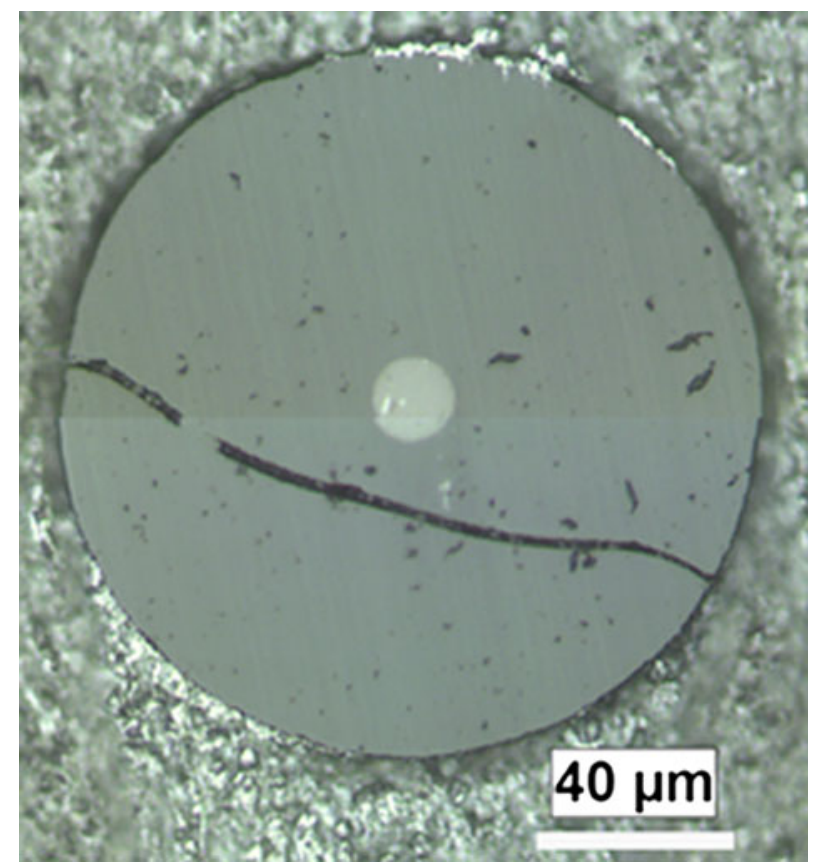

Fig. 4 Cross-section of a boron fiber after $10 \mathrm{~min}$ of immersion in molten aluminum containing $500 \mathrm{ppm} \mathrm{Ti}$ at $1013 \mathrm{~K}\left(740^{\circ} \mathrm{C}\right)$. The fiber remained in the melt during solidification.

filament was introduced into an aluminum melt containing $500 \mathrm{ppm} \mathrm{Ti}$ at $1013 \mathrm{~K}\left(740{ }^{\circ} \mathrm{C}\right)$, maintained in the melt for 15 minutes and then rapidly withdrawn. Figure 5 shows a TEM image of the filament/aluminum interface and Figure 6 illustrates the elemental line scan across this interface following the $\mathrm{a}-\mathrm{b}$ path. Aluminum was detected in the boron filament indicating that it diffuses rapidly within boron. A strong peak of oxygen was also detected at the interface. The source of oxygen could be an oxide skin entrained from the melt surface or oxygen at the surface of the boron filament, usually in the form of boron oxide, most likely combined as aluminum oxide after immersion. A very weak peak of titanium was also detected at the interface after long counting times. The massive phase formed in front of the interface was 


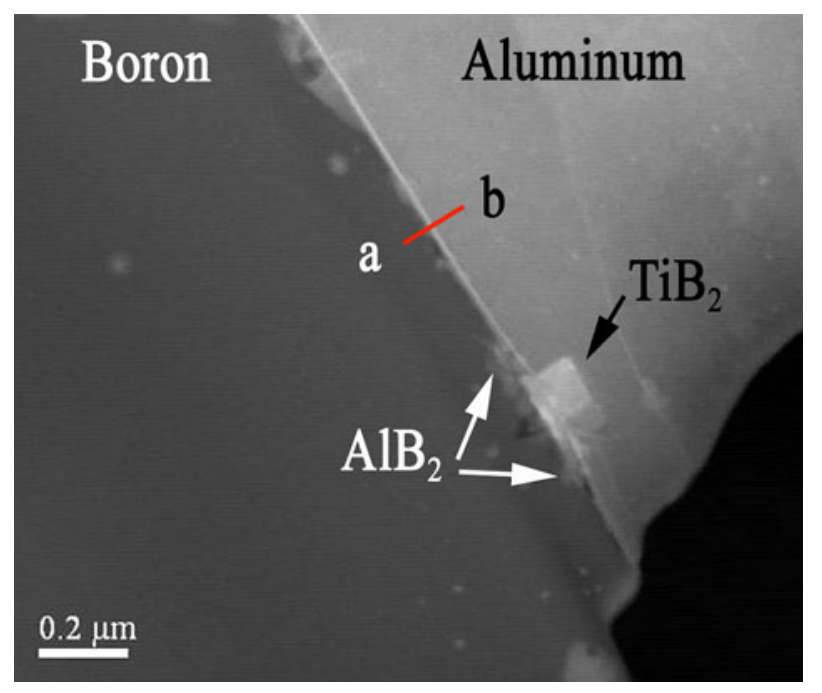

Fig. 5-Boron-aluminum interface with the reaction interlayer revealing the formation of $\mathrm{AlB}_{2}$ and $\mathrm{TiB}_{2}$ phases. The fiber was immersed in aluminum melt containing $500 \mathrm{ppm}$ Ti for $15 \mathrm{~min}$ at $1013 \mathrm{~K}\left(740{ }^{\circ} \mathrm{C}\right)$ and rapidly withdrawn.

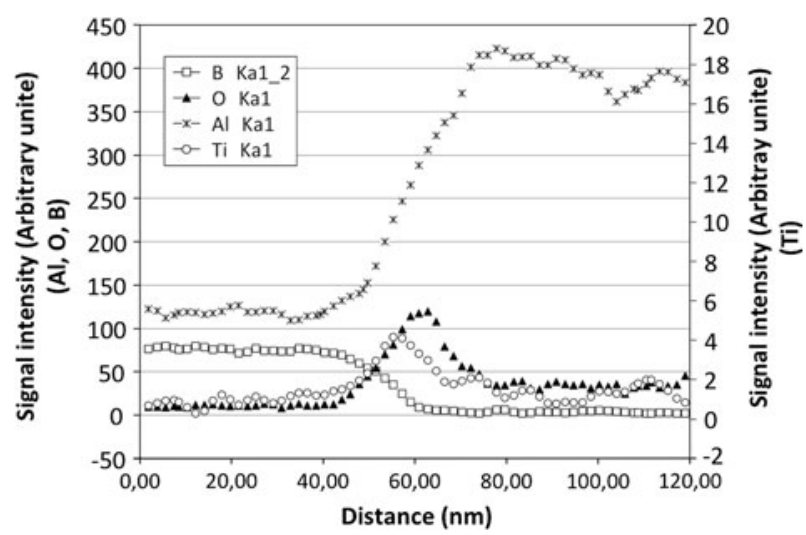

Fig. 6-Elemental profile across the boron-aluminum interface along the a-b path shown in Fig. 5. The concentrations of aluminum, boron, and oxygen are read on the left axis and that of titanium on the right one.

identified as $\mathrm{TiB}_{2}$ using electron diffraction. The gray zones just behind the interface were identified as $\mathrm{AlB}_{2}$.

The interface was also examined after immersion in the melt for 6 hours following the same procedure. Figure 7 shows a dark field TEM image of the interface. Compared to the interface after 15 minutes of immersion (Figure 5), 6 hours of immersion results in a continuous layer of $\mathrm{TiB}_{2}$ blocky crystals in front of the interface while the gray $\mathrm{AlB}_{2}$ zone behind the interface was thickened (Figure 7). Figure 8a shows the electron diffraction pattern obtained in the gray zone behind the interface (inside boron filament) and corresponds to $\mathrm{AlB}_{2}$ structure. The electron diffraction pattern shown in Figure $8 \mathrm{~b}$ were obtained in the blocky crystals in front of the interface and corresponds to $\mathrm{TiB}_{2}$. Variations in the thickness of $\mathrm{AlB}_{2}$ zone indicate that the rate of diffusion of $\mathrm{Al}$ in boron is not the same along the interface. This could be attributed to surface defects and asperities on the boron filament.

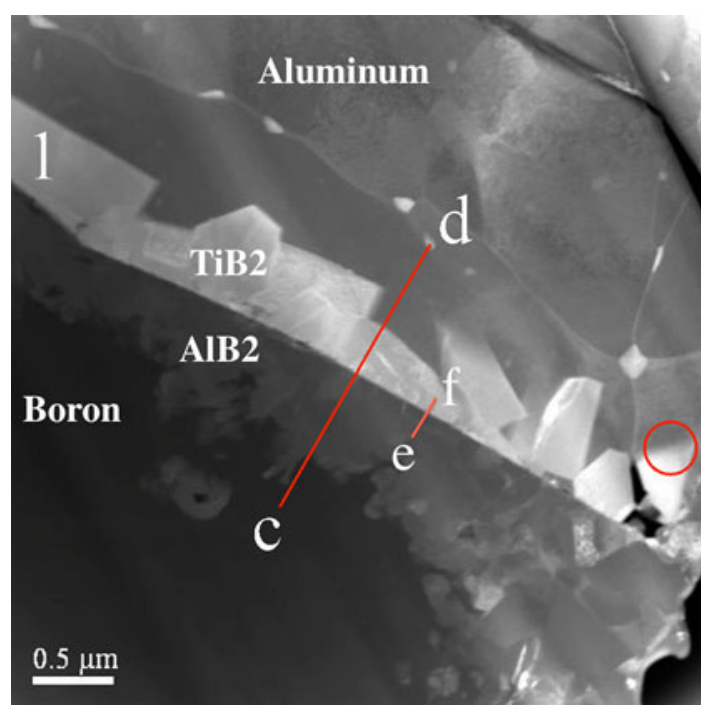

Fig. 7-Boron-aluminum interface with the reaction interlayer revealing the formation of $\mathrm{AlB}_{2}$ and $\mathrm{TiB}_{2}$ phases. The boron fiber was immersed for $6 \mathrm{~h}$ in aluminum melt containing $500 \mathrm{ppm} \mathrm{Ti}$ at $1013 \mathrm{~K}\left(740^{\circ} \mathrm{C}\right)$ and rapidly withdrawn from the melt. The circled area is further examined in $æ$.

Figure 9 shows the elemental distribution of aluminum, boron, titanium and oxygen across the interface over a $2.5 \mu \mathrm{m}$ length (c-d path in Figure 7). The boron signal has been amplified in order to reveal the details (its intensity is read on the right axis). From point $\mathrm{c}$ in the boron fiber, it is found that the aluminum concentration increases once the probe enters in the gray zone and then it decreases rapidly to almost zero in the $\mathrm{TiB}_{2}$ crystal. The boron concentration, on the other hand, decreases over the gray zone, increases slightly on $\mathrm{TiB}_{2}$ crystal and then decreases to zero in aluminum zone. It can also be noted that titanium concentration increases drastically over the blocky crystal and decreases to almost zero level over aluminum. In contrast with aluminum, there is no evidence of diffusion of $\mathrm{Ti}$ inside the boron filament and all titanium remains in front of the interface.

The $\mathrm{AlB}_{2} / \mathrm{TiB}_{2}$ interface was re-analyzed using a better resolution in order to enhance the oxygen concentration profile (Figure 10). The approximate zone of analysis is indicated as e-f path in Figure 7 and corresponds to the dashed rectangular zone in Figure 9. It can be seen that an oxide layer is present at the interface and acts as a marker since it does not change its position with time as compared with Figure 6. This peak is a good indicator for initial boron/melt interface.

Titanium and boron concentrations overlap over a short distance of about $50 \mathrm{~nm}$ and could indicate the existence of an $(\mathrm{Al}, \mathrm{Ti}) \mathrm{B}_{2}$ phase. However, the presence of two distinct phases of $\mathrm{TiB}_{2}$ and $\mathrm{AlB}_{2}$ with a relatively sharp interface indicates that, at this temperature, these two phases do not form a continuous solid solution. Similar conclusions had been reported by other authors. ${ }^{[20,21]}$ The Ti and boron overlap is therefore more probably an artifact due to the low spatial resolution of the EDX probe and the fact that the interface is barely parallel to the electron trajectory. 


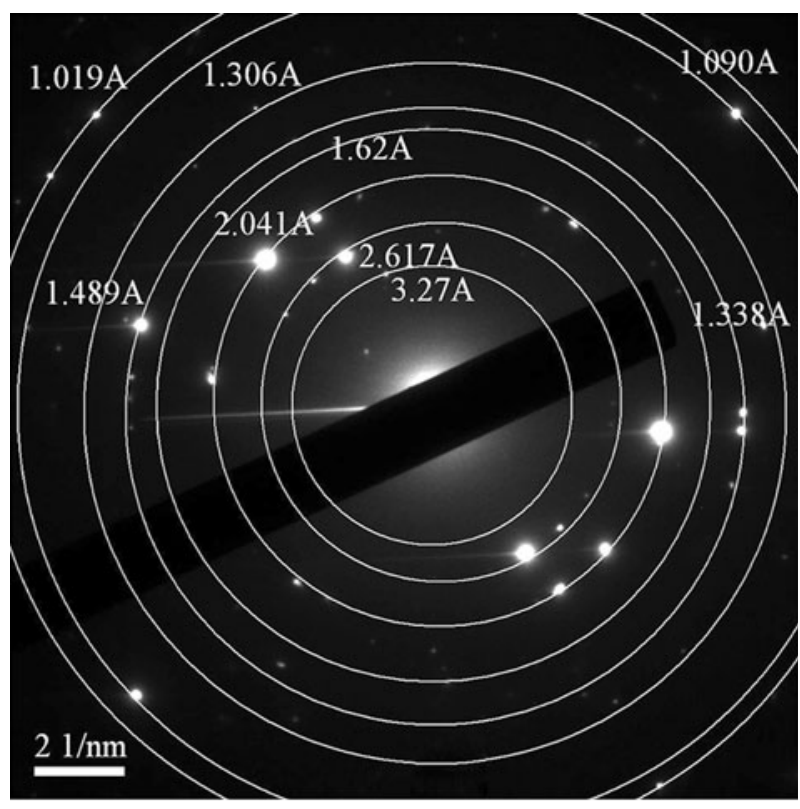

(a)

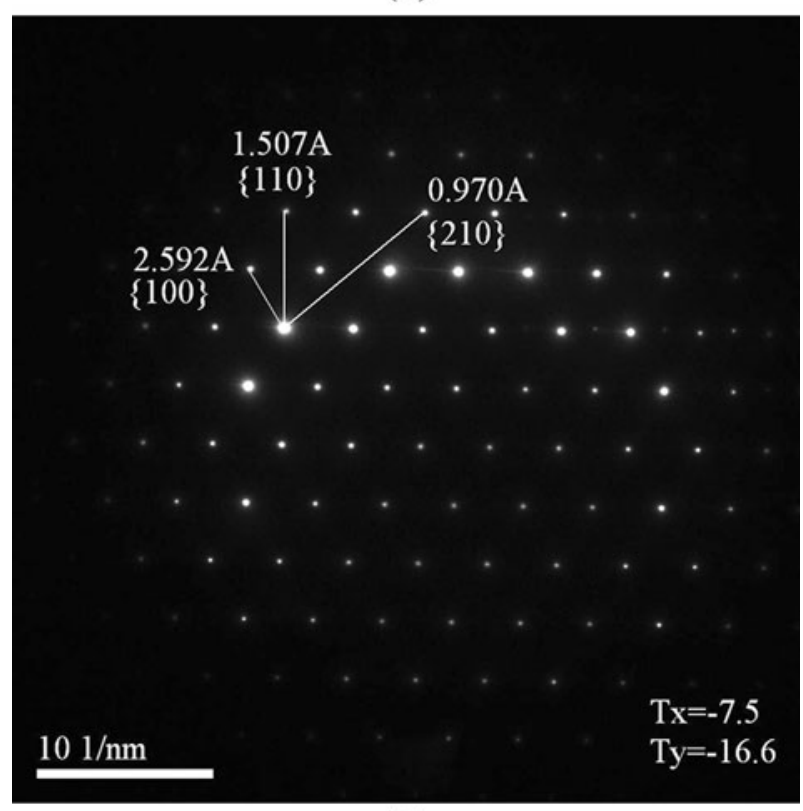

(b)

Fig. 8-Electron diffraction pattern of $(a)$ the gray zone behind the interface corresponding to $\mathrm{AlB}_{2}$ and $(b)$ the blocky crystals identified as $\mathrm{TiB}_{2}$.

It is clear that $\mathrm{Al}$ diffuses through the $\mathrm{TiB}_{2}$ and oxide layers and thickens the $\mathrm{AlB}_{2}$ zone behind the initial interface. No evidence of $\mathrm{Al}$ gradient within $\mathrm{TiB}_{2}$ crystals was observed in our experiment. Since $\mathrm{TiB}_{2}$ and AlB2 are not soluble in each other, the diffusion of $\mathrm{Al}$ through $\mathrm{TiB}_{2}$ crystals is hardly conceivable. It is therefore logical to suppose that the diffusion of $\mathrm{Al}$ takes place through the $\mathrm{TiB}_{2}$ grain boundaries. It can also be seen that the thickness of $\mathrm{AlB}_{2}$ is not homogeneous over the examined areas. This is thus probably due to the $\mathrm{TiB}_{2}$ grain boundary defects in some areas favoring the diffusion of aluminum (interface on the

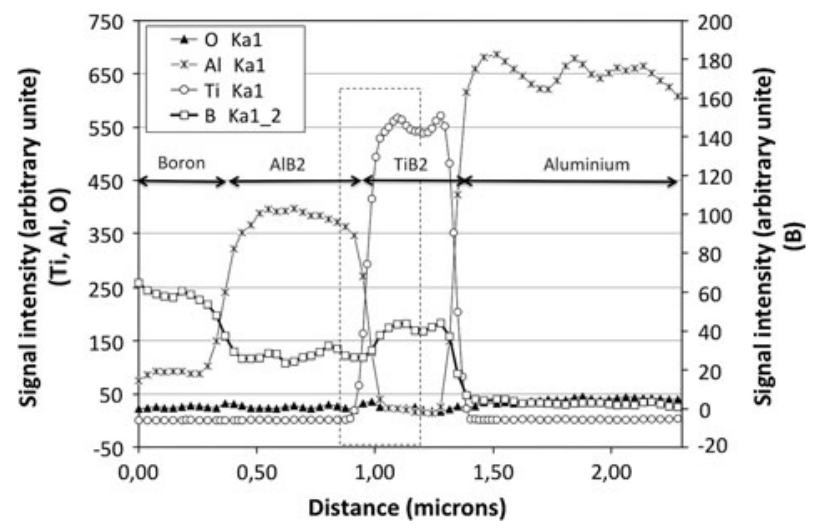

Fig. 9-Elemental linescan across the boron-aluminum interface along the c-d path shown in Fig. 7. The concentrations of aluminum, oxygen, and titanium are read on the left axis and that of boron on the right one. The arrows show four distinguished zones corresponding to different phases identified in Fig. 7.

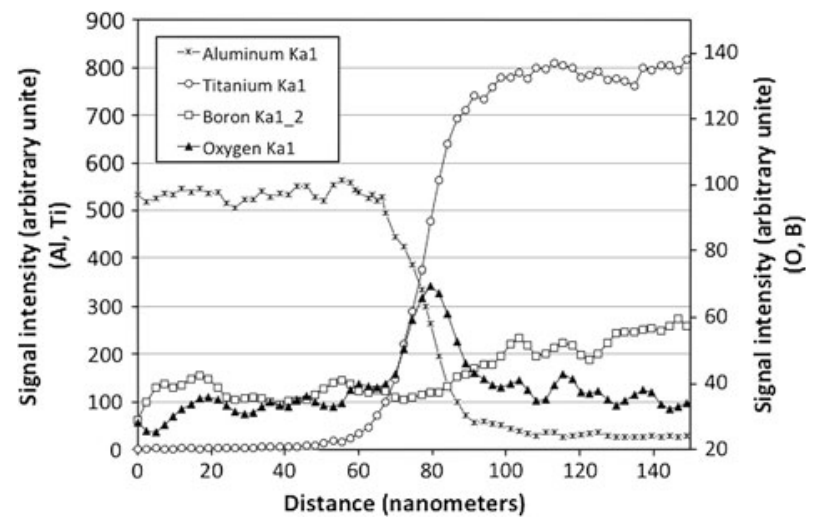

Fig. 10-Detail of the elemental composition profile at the $\mathrm{AlB}_{2}$-Ti$\mathrm{B}_{2}$ along e-f path interface shown in Fig. 7. The concentrations of aluminum and titanium are read on the left axis and that of boron and oxygen on the right one, as indicated by arrows.

right side of Figure 7). In the same way, boron can diffuse through $\mathrm{AlB}_{2}$ and at $\mathrm{TiB}_{2}$ grain boundaries to reach the solid/liquid interface and react with titanium solute to thicken the $\mathrm{TiB}_{2}$ layer. Actually the relative position of oxygen peak confirms this hypothesis since $\mathrm{TiB}_{2}$ crystals were detected only in front of this peak.

Although these experiments revealed the mechanisms by which boron is protected in aluminum melt containing titanium, they do not clarify the grain refining mechanism of elemental boron particles as reported earlier. ${ }^{[19]}$ The $\mathrm{Al} / \mathrm{TiB}_{2}$ interface was examined using TEM to obtain more information about the solidification of aluminum over the $\mathrm{TiB}_{2}$ layer formed in situ. The area encircled in Figure 7 was further examined at higher magnification where a crystal of Al was found at the vicinity of a $\mathrm{TiB}_{2}$ crystal. The inter-planar spacing of $\mathrm{TiB}_{2}(001)$ and $\mathrm{Al}$ (111) planes were measured to be 0.262 and $0.230 \mathrm{~nm}$, respectively. The angle between these two planes was measured to be $14.9 \mathrm{deg}$ and the interface was found to be clear and free from any transitional phase. However no evidence of coherency between aluminum and $\mathrm{TiB}_{2}$ was observed. 
Examination of other $\mathrm{TiB}_{2} / \mathrm{Al}$ interfaces did not reveal any coherent interface.

\section{Possible Refining Mechanism}

As mentioned earlier, the objective of this work was to understand how elemental boron particles act as an efficient grain refiner for aluminum alloys as reported by Alamdari et al. ${ }^{[19]}$ At the light of this experiment, the refining mechanism of elemental boron seems to be close to that of Al-Ti-B master alloys and it can be attributed to the nucleation of $\mathrm{Al}$ directly on $\mathrm{TiB}_{2}$ particles.

Grain refining mechanism of Al-Ti-B master alloys has been ardently disputed in the literature for more than 20 years. The microstructure of these master alloys consists basically of two phases within an aluminum matrix; $\mathrm{TiB}_{2}$ and $\mathrm{TiAl}_{3}$. The refining mechanism is therefore attributed to the nucleation of aluminum on either one of these phases. Two major hypotheses have been put forward and supported by some experimental observations to explain the refining phenomenon. The first one considers that aluminum can directly nucleate on certain crystallographic planes of a $\mathrm{TiB}_{2}$ crystal while the second one only considers the nucleation of aluminum on $\mathrm{TiAl}_{3}$.

Mohanthy et al.$^{[12,22]}$ showed that when Ti is absent, synthetic $\mathrm{TiB}_{2}$ particles added to molten aluminum are pushed at the grain boundaries rather than being present within grains. Kaneko et al. ${ }^{[23]}$ also reported that $\mathrm{TiB}_{2}$ alone is not an efficient grain refiner.

Easton and StJohn ${ }^{[24]}$ showed that $\mathrm{TiB}_{2}$ are effective nucleants while the excess $\mathrm{Ti}$ solute restricts grain growth providing constitutional undercooling. Powerful refining effect of a master alloy, where both $\mathrm{TiB}_{2}$ and $\mathrm{Ti}$ are present, led to development of the duplex nucleation theory. Mohanty and Gruzleski ${ }^{[12]}$ detected a thin Ti-rich layer around the synthetic $\mathrm{TiB}_{2}$ particles using electron probe micro analysis technique. The surrounding layer had a chemical composition close to $\mathrm{TiAl}_{3}$. A crystallographic approach has also been used to explain the grain refining mechanisms. Detection of an epitaxial layer, with lattice spacing consistent with $\mathrm{TiAl}_{3}$, on $\mathrm{TiB}_{2}$ particles led Schumacher et al. ${ }^{[15]}$ to conclude that such a layer could be responsible for heterogeneous nucleation of aluminum. The refining effect was thus attributed to the formation of a $\mathrm{TiAl}_{3}$ layer on $\mathrm{TiB}_{2}$ particles.

Low lattice disregistry between aluminum and $\mathrm{TiAl}_{3}$ compared to that between aluminum and $\mathrm{TiB}_{2}{ }^{[1]}$ suggests a superior nucleation potential of the former but it does not exclude the refining potential of the latter. The interface between $\mathrm{Al}$ and $\mathrm{TiB}_{2}$ was investigated by several authors but a consensus has not been yet reached regarding the existence of an orientation relationship between these two phases. An orientation relationship between (111) $\mathrm{Al}$ and (0001) $\mathrm{TiB}_{2}$ planes was found in a melt-spun Al-5Ti-1B master alloy. ${ }^{[25]}$ Mitra et al. ${ }^{[26]}$ and Kostka et al. ${ }^{[27]}$ reported semicoherent interface between $\mathrm{TiB}_{2}$ and $\mathrm{Al}$ where no reaction layer or segregation were found. Although these data show the good potential of certain planes of $\mathrm{TiB}_{2}$ for nucleation of aluminum, the experimental conditions prevailing in these works are far from those of grain refining process. It is therefore difficult to extrapolate directly these observations to explain the grain refining process in aluminum alloys.

The interface between $\mathrm{Al}$ and $\mathrm{TiB}_{2}$ crystals examined in the present work simulates very closely the real grain refining conditions of boron particles reported earlier ${ }^{[19]}$ A clean interface without any consistent crystallographic orientation between $\mathrm{TiB}_{2}$ and $\mathrm{Al}$ matrix was revealed. This observation suggests that the presence of a $\mathrm{TiAl}_{3}$ intermediate layer is not essential for nucleation; hence Al nucleates directly from the $\mathrm{TiB}_{2}$ crystals formed in situ on boron particles in the melt. Consequently, in grain refining experiments with elemental boron particles, it is speculated that each boron particle acts as a substrate for nucleation of several $\mathrm{TiB}_{2}$ crystallites as shown in Figures 5 and 7. These crystallites with different crystallographic orientations increase the probability of exposing a suitable $\mathrm{TiB}_{2}$ facet, having minimum interface energy with $\alpha$-Al, and result in higher refining efficiency of a single boron particle. It is probably the reason why elemental boron shows a higher efficiency than the conventional grain refiner with equivalent $\mathrm{Ti}$ and $\mathrm{B}$ addition levels. Another important role of $\mathrm{TiB}_{2}$ crystallites is to protect boron particles and prevent their dissolution in aluminum melt.

Boron-based refiner may offer other considerable advantages compared to the conventional ones. ${ }^{[19]}$ For grain refining of recycled aluminum already containing $\mathrm{Ti}$, no further addition of $\mathrm{Ti}$ is required. In addition, no potassium fluoride salts are required in the manufacturing process, overcoming the agglomeration of $\mathrm{TiB}_{2}$ particles associated with these salts. The boron particle size can be controlled during manufacturing eliminating the problems encountered with large $\mathrm{TiB}_{2}$ particles. $\mathrm{A} \mathrm{TiB}_{2}-$ shielded boron particle has a lower density than a bulk $\mathrm{TiB}_{2}$ particle and settle less rapidly in liquid aluminum than bulky $\mathrm{TiB}_{2}$ does.

\section{CONCLUSIONS}

In this paper, the grain refining mechanism of boron particles was studied by observing the behavior of boron filaments immersed in Al-Ti melts in different conditions. Boron filaments were immersed into liquid aluminum having different concentrations of titanium (between 0 and $500 \mathrm{ppm}$ ) and the microstructure and composition at the $\mathrm{B} / \mathrm{Al}$ interface were investigated. Boron filament was used to facilitate the observation of the Al-B interface.

The results showed that boron dissolves rapidly in pure aluminum. However, a concentration of about $100 \mathrm{ppm}$ of $\mathrm{Ti}$ inhibits its dissolution. When boron comes in contact with titanium containing melts a thin layer of $\mathrm{TiB}_{2}$ crystallites is formed at the surface of boron and protects it from dissolution. The boron surface is therefore covered with very fine $\mathrm{TiB}_{2}$ crystals having different crystallographic orientations. The $\mathrm{TiB}_{2}$ layer thickens as the boron residential time in the melt increases. Aluminum on the other hand, diffuses 
through the $\mathrm{TiB}_{2}$ layer and reacts with boron to form $\mathrm{AlB}_{2}$ behind the $\mathrm{TiB}_{2}$ layer.

During solidification, aluminum crystallizes on this in situ formed $\mathrm{TiB}_{2}$ layer. The interface between $\mathrm{TiB}_{2}$ and aluminum was found to be clean and free from $\mathrm{TiAl}_{3}$ or any transitional phase. A disregistry of $15 \mathrm{deg}$ was revealed between (111) Al plane and (100) $\mathrm{TiB}_{2}$ plane. These observations suggest that the grain refining effect of boron is most likely due to the presence of this $\mathrm{TiB}_{2}$ layer.

When a boron-based grain refiner is added to an aluminum melt, boron particles are released into the melt and a large number of $\mathrm{TiB}_{2}$ crystallites with different crystallographic orientations are formed in situ on the surface of these boron particles. These diverse orientations increase the probability of exposing a suitable $\mathrm{TiB}_{2}$ plane, (0001) planes for instance, having minimum interface energy with $\alpha-\mathrm{Al}$ and result in nucleation of aluminum. This may explain why elemental boron show a higher efficiency than the conventional grain refiner with equivalent $\mathrm{Ti}$ and $\mathrm{B}$ addition levels as reported in the literature.

\section{ACKNOWLEDGMENTS}

The financial support of this project was provided by the "Natural Sciences and Engineering Research Council of Canada (NSERC)" and "Fonds de Recherche du Québec - Nature et Technologies (FRQ-NT)" via the Aluminum Research Centre-REGAL. The authors wish to acknowledge the contribution of Specialty Materials Inc., for providing the boron filaments, of Mr. H. Heidari for his contribution in some experiments and of Dr. Z. Zhang, Université du Québec à Chicoutimi, for TEM analysis.

\section{REFERENCES}

1. T.E. Quested: Mater. Sci. Technol., 2004, vol. 20, pp. 1357-69.

2. A.L. Greer: Phil. Trans. R. Soc. Lond., 2003, vol. A361 (1804), pp. $479-94$.

3. B. Cantor: Phil. Trans. R. Soc. Lond., 2003, vol. A361 (1804), pp. $409-16$.
4. A.L. Greer, P.S. Cooper, M.W. Meredith, W. Schneider, P. Schumacher, J.A. Spittle, and A. Tronche: Adv. Eng. Mater., 2003, vol. 5 (1-2), pp. 81-91.

5. B.S. Murty, S.A. Kori, K. Venkateswarlu, R.R. Bhat, and M. Chakraborty: J. Mater. Process. Technol., 1999, vol. 90, special issue, pp. $152-58$

6. J.A. Marcantonio and L.F. Mondolfo: Metall. Trans., 1971, vol. 2, pp. $465-71$.

7. G.P. Jones and J. Pearson: Metall. Trans. B, 1976, vol. 7B, pp. 223-34.

8. P.S. Mohanty and J.E. Gruzleski: Acta Mater., 1996, vol. 44 (9), pp. 3749-60.

9. K. Venkateswarlu, B.S. Murty, and M. Chakraborty: Mater. Sci. Eng., 2001, vol. A301, pp. 180-86.

10. M. Johnsson: Light Metals, The Minerals, Metals and Materials Society, Warrendale, PA, 1992, pp. 769-77.

11. G.P. Jones: Solidification Processing, The Institute of Metals, Sheffield, 1987, pp. 496-99.

12. P.S. Mohanty and J.E. Gruzleski: Acta Metall. Mater., 1995, vol. 43 (5), pp. 2001-12.

13. P. Schumacher and A.L. Greer: Mater. Sci. Eng., 1994, vol. A178, pp. 309-13.

14. P. Schumacher and A.L. Greer: Mater. Sci. Eng., 1994, vol. A181/ A182, pp. 1335-39.

15. P. Schumacher, A.L. Greer, J. Worth, P.V. Evans, M.A. Kearn, P. Fisher, and A.H. Green: Mater. Sci. Technol., 1998, vol. 14, pp. 394-404.

16. T. Gudmundsson, T.I. Sigfusson, D.G. McCartney, E. Wuilloud, and P. Fisher: Light Metals, The Minerals, Metals and Materials Society, Warrendale, PA, 1995, pp. 851-54.

17. T. Gudmundsson, G. Saevarsdottir, T.I. Sigfusson, and D.G. McCartney: Light Metals, Reidar Huglen, ed., The Minerals, Metals and Materials Society, Warrendale, PA, 1997, pp. 851-55.

18. K.R. Ravi, S. Manivannan, G. Phanikumar, B.S. Murty, and S. Sundarraj: Metall. Mater. Trans. A, 2011, vol. 42A, pp. 2028-39.

19. H. Alamdari, J. Larouche, and S. Boily: Fonderie Fondeur d'Aujourd'hui, 2002, vol. 217, pp. 32-42.

20. J. Fjellstedt and A.E.W. Jarfors: Z. Metallkd, 2001, vol. 92 (6), pp. 563-71.

21. F. Zupanic, S. Spaic, and A. Krizman: Mater. Sci. Technol., 1998, vol. 14 (7), pp. 601-07.

22. P.S. Mohanty, F.H. Samuel, J.E. Gruzleski, and T.J. Kosto: Light Metals, U. Mannweiler, ed., The Minerals, Metals and Materials Society, Warrendale, PA, 1994, pp. 1039-45.

23. J. Kaneco, M. Sugamata, R. Shimamune, and S. Seshan: Trans. Jpn. Foundrymen's Soc., 1991, vol. 10, pp. 72-75.

24. M. Easton and D. St John: Metall. Mater. Trans. A, 1999, vol. 30A, pp. 1625-33.

25. Y. Yang, Z. Zhang, W. Wang, and X. Bian: Mater. Sci. Eng., 2004, vol. A366, pp. 17-24.

26. R. Mitra, W.A. Chiou, M.E. Fine, and J.R. Weertman: J. Mater. Res., 1993, vol. 8 (9), pp. 2380-92.

27. A. Kostka, J. Lelatko, M. Gigla, H. Morawiec, and A. Janas: Mater. Chem. Phys., 2003, vol. 81, pp. 323-25. 